\title{
visita de la profesora Dra. Miriam Ramos
}

Entre el 6 al 10 de marzo del presente año visitó la Pontificia Universidad Católica de Chile la Profesora Dra. Miriam Ramos Gómez, de la Universidad Católica de Ávila, España. Fue invitada especial a las sesiones de uno de los cinco grupos de investigación del Centro UC de Estudios interdisciplinarios Edith Stein. El proyecto en el que vino a participar se titula: "LA ANGUSTIA INCONSCIENTE DE ENCONTRARSE CON DIOS": Aproximación sistemática a los comentarios de Edith Stein a Teresa de Ávila y Martín Heidegger, comparados con el pensamiento de Víctor Frankl", correspondiente al Proyecto Fondecyt Regular 2016-2017/ 1160122.

El título del proyecto procede de una expresión de Edith Stein, en el Castillo Interior, Anexo 1 de su obra Ser Finito y Ser eterno. La hipótesis, que orienta la investigación, puede enunciarse así: La angustia inconsciente de encontrarse con Dios impide a la ciencia alcanzar la verdadera identidad propia, al desconocer la experiencia originaria del ser humano en el mundo. Esta situación se superaría por un análisis adecuado de tal experiencia en cuanto propia del espiritu finito anticipado por el Espiritu Infinito.

Esta angustia emerge de la experiencia originaria del ser humano en el mundo, que es entonces anterior al proceder categorial del quehacer científico. La ciencia cuenta, entonces, con un sustrato inconsciente que, para su propia identidad científica, debería aclarar en cuanto a sus presupuestos y también al instrumental conceptual que emplea.

La primera sesión se tituló $L a$ critica de la psicología del siglo XX en Edith Stein y Viktor Frankl, donde aclaró los presupuestos científicos de la Psicología, de la Filosofía y de la Teología que subyacen a las críticas de Edith Stein y Víctor Frankl a la psicología del siglo XX. Tal Psicología trabaja, efectivamente, aunque de modo inconsciente, con categorías ajenas a su índole propia al proceder según el modelo de las llamadas "ciencias exactas", aunque ella sea, etimológicamente, una "ciencia del alma”, es decir, una ciencia del espíritu. En estas condiciones, se ha transformado, según Edith Stein, en una "psicología sin alma". 
El uso de un instrumental científico inadecuado, puede distorsionar los resultados de las ciencias del espíritu, sobre todo, en lo referente al concepto de causalidad y a su origen en Dios. Esta causalidad, no debe ser comprendida como física, e.d., como producida por intervenciones desde fuera, sino en cuanto orientada por la motivación, un concepto propio de las ciencias del espíritu. En Edith Stein, esto es una confusión inconsciente entre las ciencias exactas y las ciencias del espíritu.

Después analizó la profesora Ramos la falta de fundamentos de la psicología, según Víctor Frankl, explicando la respuesta a esta crítica por la psicoterapia a partir de la importancia del sentido y de la responsabilidad, resistiendo así a la naturalización de la conciencia moral por la impulsividad.

La insistencia de Ramos en la "reducción del inconsciente" tanto en Freud como en Jung, resultó iluminadora para un mayor conocimiento la comprensión científica de este concepto difícil, este fue un avance significativo para la investigación.

En la segunda sesión presentó la Respuesta de Edith Stein al idealismo trascendental de Edmund Husserl, como aporte para aclarar la relación y diferencia entre el Maestro y la discípula desde de una comparación del concepto de lo inteligible en el De veritate de Tomás de Aquino y en Husserl. Aunque queda pendiente de la comprensión de un retorno husseliano al idealismo trascendental y su rechazo por Edith Stein. Pareciera que Stein no rechazó el giro del pensamiento de Husserl al final de su vida, sino lo completó desde la intuición originaria del Maestro.

Queda pendiente una mayor aclaración del aporte novedoso de Edith Stein en vista a la comprensión de la angustia. Dicha angustia es un fenómeno originario distinto al que Martín Heiddeger llama "angustia" ya que la angustia steineana no proviene de "la nada", sino de una privación de plenitud, impregnada por la alegría de existir.

La tercera sesión, titulada El concepto de voluntad de sentido en Viktor Frankl a la luz de la fllosofía de Edith Stein, fue dedicada a explorar las semejanzas y diferencias de Edith Stein y Víctor Frankl. Aunque ambos mantienen que la verdad no se inventa sino que "existe", Stein tiene una visión de la realidad objetiva que me es dada, y Frankl parece favorecer la creación subjetiva del "sentido" que influirá también en la responsabilidad ética del comportamiento individual y colectivo ante el fenómeno de la angustia.

Anneliese Meis

Facultad de Teología Pontificia Universidad Católica de Chile 